\title{
Fibrohistiocitoma conjuntival simulando pterígio atípico na região amazônica: relato de caso
}

\author{
Conjunctival fibrous histiocytoma simulating atipical pterygium in the Amazon region: \\ case report
}

Roberto Murillo Limongi de Souza Carvalho ${ }^{1}$, Alexandre Taleb ${ }^{1}$, Giulianna limongi de Souza Carvalho ${ }^{1}$, Marcos Ávila ${ }^{1}$

\section{RESUMO}

Relatamos um caso inédito na literatura brasileira de fibrohistiocitoma conjuntival descoberto durante projeto comunitário de larga escala realizado pela equipe do Centro de Referência em Oftalmologia do Hospital das Clínicas da Universidade Federal de Goiás na região amazônica. Paciente do sexo feminino, leucoderma, de 38 anos de idade, apresentava lesão vascularizada no olho direito no canto medial da conjuntiva bulbar e carúncula com extensão para o limbo e invadindo cerca de $2 \mathrm{~mm}$ da córnea medial com configuração semelhante a um pterígio. O exame histopatológico revelou lesão constituída por células fusiformes, com arranjo estoriforme e células histiocitárias gigantes. A imunohistoquímica revelou forte positividade para vimentina e as células neoplásicas foram negativas para AE1/ AE3, HMB 45, proteína S 100. O diagnóstico histopatológico foi de fibrohistiocitoma. A evolução poderá demonstrar o crescimento tumoral e a possibilidade de lesão maligna.

Descritores: Histiocitoma fibroso benigno; Pterígio; Neoplasias da túnica conjuntiva/diagnóstico; Imuno-histoquímica; Vimentina; Relatos de casos; Humano; Feminino; Adulto

\begin{abstract}
An inedited case in the Brazilian literature of conjunctival fibrous histiocytoma discovered during a wide scale community project accomplished by the team of the Center of Reference in Ophthalmology of the Hospital das Clínicas da Universidade Federal de Goiás in the Amazon region is reported. A 38 year-old caucasian woman presented with a vascularized lesion on the medial portion of the bulbar conjunctiva and caruncular region of the right eye with extension for the limbus and invading about $2 \mathrm{~mm}$ of the medial cornea resembling a pterygium. Pathologic findings revealed that the lesion was constituted by spindle-shaped cells, with storiform arrangement, and large histocytelike cells. The immunohistochemistry revealed strong positivity for vimentin and the neoplastic cells were negative for AE1/AE3, HMB 45, S 100 protein. The histopathologic diagnosis was fibrous histiocytoma. The evolution demonstrated the tumoral growth and the possibility of a malignant lesion.
\end{abstract}

Keywords: Histiocytoma, benign fibrous; Pterygium; Conjunctival neoplasms/ diagnosis; Vimentin; Immunohistochemistry; Case reports; Human; Male; Adult

\section{INTRODUÇÃO}

$\mathrm{F}$ ibrohistiocitomas representam um grupo heterogêneo de tumores mesenquimais compostos por uma mistura de elementos fibroblásticos e histiocíticos em quantidades variáveis e em diferentes graus de diferenciação ${ }^{(1)}$. $\mathrm{O}$ acometimento ocular ocorre frequentemente na órbita, porém raramente pode acometer a conjuntiva(2-7).

Neste presente relato descrevemos um caso inédito na literatura brasileira de um fibrohistiocitoma conjuntival em uma muIher de 38 anos de idade, natural da região amazônica, diagnosticado durante Projeto Catarata realizado pela equipe do Centro de Referência em Oftalmologia do Hospital das Clínicas da Universidade Federal de Goiás no município de Almeirim - Pará.

Este relato é de interesse por duas razões: em primeiro lugar, descreve os sinais clínicos, histopatológicos e imuno-histoquímicos de patologia pouco conhecida que é o fibrohistiocitoma conjuntival; segundo, mostra a importância do papel social dos Projetos Comunitários de Catarata desenvolvidos em locais de difícil acesso desprovidos de assistência oftalmológica.

\footnotetext{
Trabalho realizado no Departamento de Cirurgia Plástica Ocular do Centro de Referência em Oftalmologia do Hospital das Clínicas do Estado de Goiás - CEROF/HC.

${ }^{1}$ Médico, Setor de Plástica Ocular, Centro de Referência em Oftalmologia, Hospital das Clínicas, Universidade Federal de Goiás - UFG - Goiânia (GO), Brasil.

Endereço para correspondência: Roberto Murillo Limongi de Souza Carvalho. Av. T-47 q31 L3/5 Ed. Monte Carlo - Apto. 1.102 - Setor Bueno - Goiânia (GO) - CEP 74210-180 E-mail: rmurillousp@hotmail.com

Recebido para publicação em 23.09.2009

Última versão recebida em 20.12.2009
}

Aprovação em 25.12.2009

\section{RELATO DE CASO}

Paciente do sexo feminino, leucoderma, com 38 anos de idade, apresentou-se à consulta com queixa de olho vermelho e baixa de acuidade visual há cinco meses no olho direito. Ao exame a acuidade visual corrigida era de 0,3 no olho direito e 1,0 no olho esquerdo. A pressão intraocular era $10 \mathrm{mmHg}$ em ambos olhos. O olho esquerdo apresentava biomicroscopia, exame ocular externo e oftalmoscopia indireta normais. No olho direito não havia qualquer alteração coriorretiniana na oftalmoscopia binocular indireta. A biomicroscopia revelava lesão vascularizada no olho direito localizada no canto medial da conjuntiva bulbar e carúncula, com extensão para o limbo e invadindo cerca de $2 \mathrm{~mm}$ da córnea medial com configuração semelhante a um pterígio, porém a região equivalente à cabeça do "pterígio" apresentava superfície pedunculada (Figura 1). A motilidade ocular estava preservada e não foi encontrada proptose. O restante do exame oftalmológico estava dentro da normalidade. A aparência grosseira da massa simulava um pterígio atípico, porém não se enquadrava em nenhum dos tumores conjuntivais mais conhecidos. A paciente foi submetida a exérese local da lesão que infiltrava o estroma corneano. A peça cirúrgica foi colocada em formol e encaminhada para análise no Laboratório de Patologia do Hospital das Clínicas da Universidade Federal de Goiás.

\section{Achados anATOMOPATOLÓGICOS}

O espécime obtido da excisão consistia de fragmento de conjuntiva de forma irregular, medindo $0,9 \times 0,6 \times 0,5 \mathrm{~cm}$, coloração acastanhada e consistência elástica. O exame histo- 
patológico revelou lesão constituída por células fusiformes, exibindo por vezes arranjo estoriforme com atipias nucleares leves e presença de raras células histiocitárias gigantes (Figura 2). A atividade mitótica era moderada com cerca de 8 mitoses por 10 campos de grande aumento (40x). Os principais diagnósticos diferenciais, à histopatologia, eram carcinoma sarcomatóide e melanoma.

A imuno-histoquímica revelou forte positividade para vimentina. As células neoplásicas foram negativas para AE1/ AE3, HMB 45, proteína S 100.

\section{DISCUSSÃO}

O fibrohistiocitoma tem sido relatado como o tumor orbitário mesenquimal mais comum em adultos, entretanto a ocorrência deste tumor em conjuntiva e limbo corneoescleral raramente é relatada na literatura mundial ${ }^{(5)}$. Acredita-se que o fibrohistiocitoma se desenvolva a partir de uma célula mesenquimal pluripotente a qual tem a capacidade de se diferenciar tanto em fibroblastos como em histiócitos ${ }^{(3)}$.

Clinicamente, o fibrohistiocitoma conjuntival pode consistir em nódulo circunscrito ou difuso com margens mal definidas, geralmente amarelado, róseo ou vermelho, levemente elevado e medindo entre 2 e $8 \mathrm{~mm}$ no seu maior diâmetro ${ }^{(3,7)}$. Neste caso, a lesão se mascarava na forma de um pterígio atípico, mantendo-se levemente elevada na região limbar, porém adquirindo forma pedunculada na região que se estendia sobre a córnea. Alguns autores já relataram o primeiro caso de fibrohistiocitoma de conjuntiva que apareceu em um paciente que apresentava pterígio(8).

O diagnóstico diferencial do fibrohistiocitoma conjuntival deve ser feito com dermóide, dermolipoma, neurofibroma, leiomiossarcoma, histiocitose $X$, rabdomiossarcoma, hemangiopericitoma, melanoma amelanótico e lesões linfoproliferativas. 0 diagnóstico definitivo é estabelecido após exame histológico e imuno-histoquímico da lesão. O exame histopatológico deste caso apresentou células fusiformes com arranjo estoriforme entremeadas com células histiocitárias, estando em acordo com os casos já relatados na literatura mundial|(8-9). $\mathrm{O}$ estudo imuno-histoquímico demonstrou forte positividade para vimentina (filamento citoplasmático intermediário encontrado na maioria de células mesenquimais) e negativo para proteína $\mathbf{S}$ 100 e citoqueratinas. Tais achados permitiram afastar as possibilidades de melanoma e carcinoma e o diagnóstico final foi de fibrohistiocitoma conjuntival.

Outros autores em estudo clínico-patológico de 150 casos de fibrohistiocitoma de órbita, classificaram este tipo de tumor em três grupos: benignos, localmente agressivos e malignos, baseados em critérios histopatológicos. Eles descreveram o comportamento biológico das lesões orbitárias que se correlacionavam intensamente com a classificação histopatológi$\mathrm{ca}^{(5)}$. Em outro trabalho autores também reportaram em sua série de casos duas formas clínicas bem definidas de fibrohistiocitoma conjuntival: benigno e maligno, baseados nos acha-

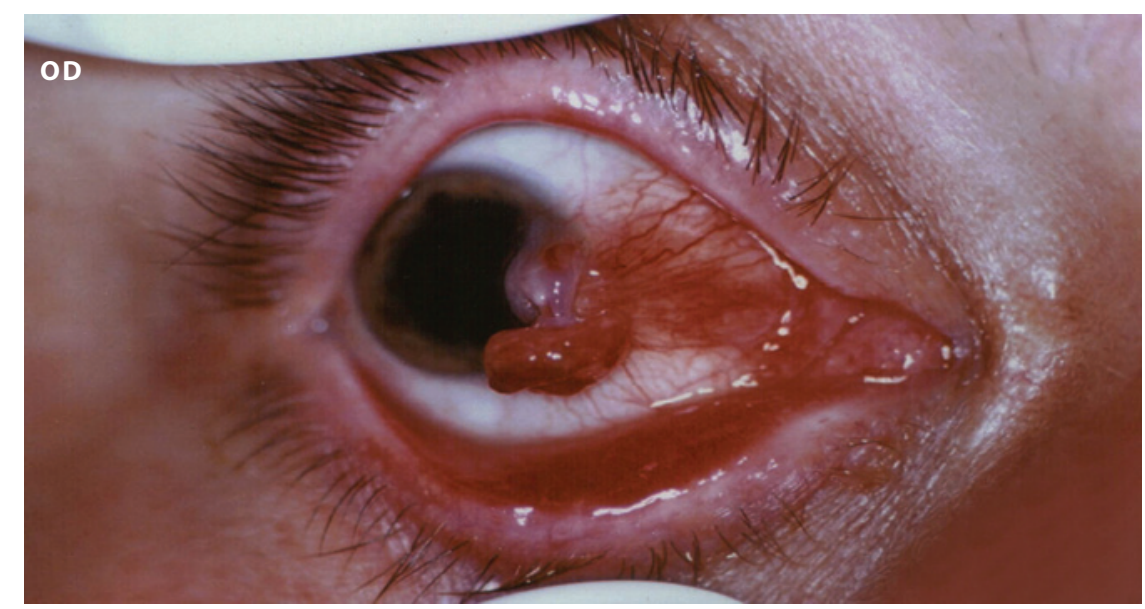

Figura 1. Aspecto externo da lesão (" em forma de cogumelo").

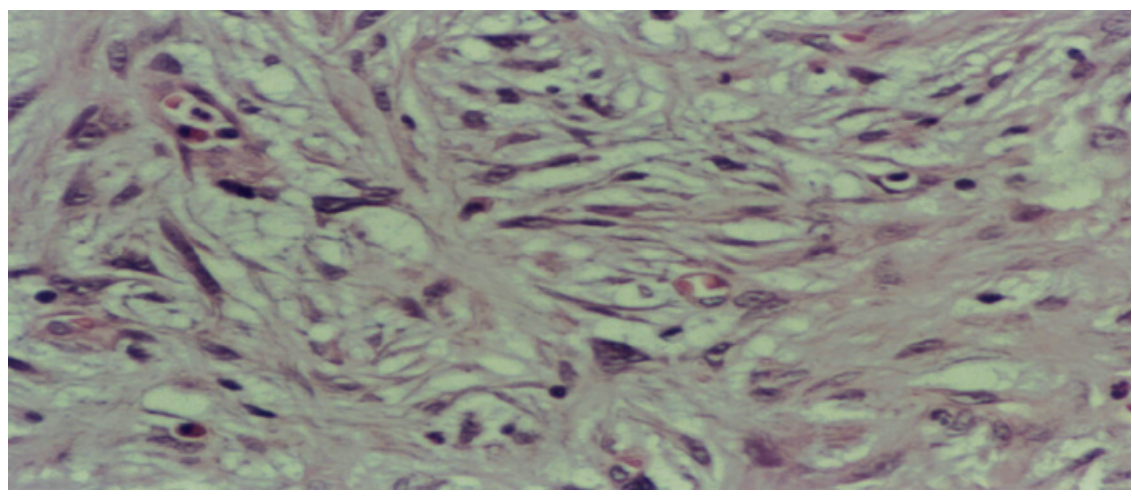

Figura 2. Exame histológico mostrando células alongadas com padrão estoriforme. 
dos histopatológicos e na evolução clínica ${ }^{(9)}$. Podemos dizer que o quadro histológico do nosso caso é condizente com o diagnóstico de fibrohistiocitoma. As atipias celulares e a superficialidade da lesão sugerem benignidade. Porém, as mitoses estão em número mais elevado do que o observado em lesões benignas. É necessária a correlação com a clínica e a evolução para definirmos a possibilidade de lesão maligna ${ }^{(8-9)}$. Como este tumor foi diagnosticado durante Projeto Catarata em agosto de 2000 na região amazônica, ainda não estão disponibilizados os achados de acompanhamento da lesão. É possível a verificação de malignidade com recidiva local ou até mesmo metástase.

Este caso fortalece a importância dos Projetos Oftalmológicos Comunitários de atendimento em larga escala de reabilitação visual que podem detectar patologias oculares de potencial cegante que ameaçam a sobrevida do paciente.

\section{REFERÊNCIAS}

1. Enzinger FM, Weiss SW. Malignant fibrohistiocytic tumors. In: Enzinger FM, Weiss SW, editors. Soft tissue umors. $3^{\text {rd }}$ ed. St Louis, Mo: Mosby; 1994. p.351-80.

2. Albert DM, Smith RS. Fibrous xanthomas of the conjunctiva. Arch Ophthalmol. 1968;80(4):474-9.

3. Flaudi JE, Kenyon K, Green WR. Fibrous histocytoma of the corneoscleral limbus. Am J Ophthalmol. 1975;80(4):619-24.

4. Iwamoto T, Jakobiec FA, Darrel RW. Fibrous histiocytoma of the corneoscleral limbus. Ophthalmology. 1981;88:1260-8.

5. Font RL, Hidayat AA. Fibrous histiocytoma of the orbit. A clinicopathologic study of 150 cases. Hum Pathol. 1982:13(3):199-209.

6. Gupta VP, Saxena T, Dev G. Fibrous histiocytoma in primary pterygium. Orbit. 2002;21(3):217-21

7. Kiratli H, Ruacan S. [Fibrous histiocytoma of the conjunctiva]. Can J Ophthalmol. 2003;38(6):504-6. French.

8. Arora R, Monga S, Mehta DK, Raina UK, Gogi A, Gupta SD. Malignant fibrous histiocytoma of the conjunctiva. Clin Experiment Ophthalmol. 2006;34(3):275-8.

9. Kim HJ, Shields CL, Eagle RC Jr, Shields JA. Fibrous histiocytoma of the conjunctiva. Am J Ophthalmol. 2006;142(6):1036-43.

\section{6을 Congresso Brasileiro de Retina e Vítreo}
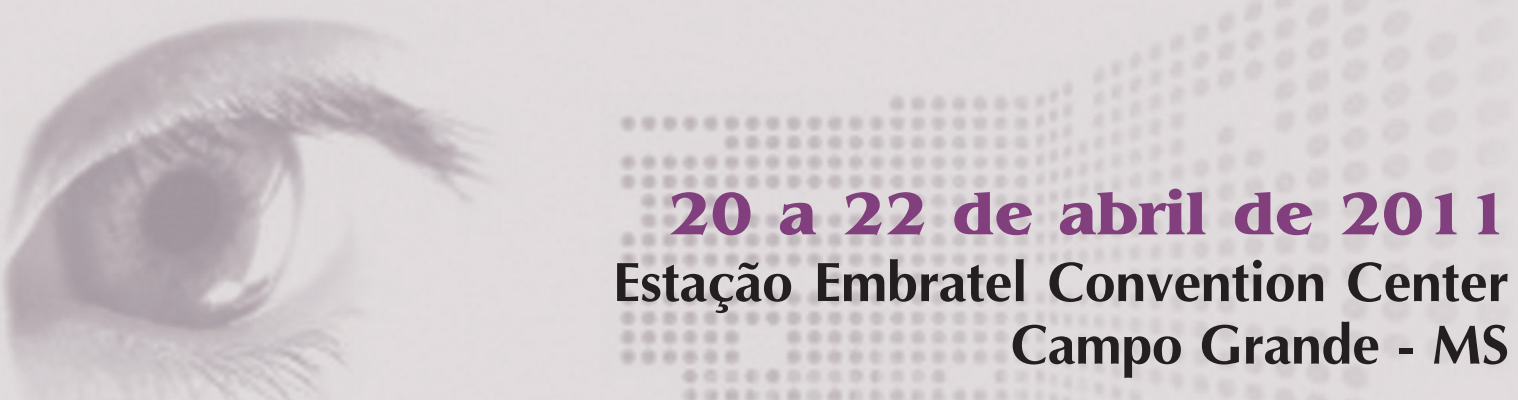

Informações:

Tel.: (11) 3849-0379

E-mail: info@meetingeventos.com.br

Site: www.retina2011.com.br 